\title{
The Variation of Carbon Nitrogen and Phosphorus and Stoichiomery Characteristics of Yili River Valley Steppe Soil under the Effects of Conyza Canadensis Invasion
}

\author{
Xifeng Zhang ${ }^{1,2}$, Dong Cui ${ }^{1,2 *}$, Haijun Yang ${ }^{1,2}$, Haijun Liu ${ }^{1,2}$ \\ ${ }^{1}$ College of Biology and Geography Sciences, Yili Normal University, Yining, PR China \\ ${ }^{2}$ Institute of Resources and Ecology, Yili Normal University, Yining, PR China
}

Received: 14 August 2020

Accepted: 25 January 2021

\begin{abstract}
Soil C, N, P and its stoichiometric ratio are important indexes to measure energy of ecosystem, multi-element equilibrium and the composition of soil organic matter. When alien plants invade, they usually change local soil environment and create an appropriate growth environment by withered fallen and scattered matters or allelopathic substances, and create an appropriate growing environment, they usually inhibit the other plants to grow and develop. In this paper, the soil of the Conyza canadensis invaded communities in different degrees in Yili River Valley is selected to study the change characteristics of carbon, nitrogen and phosphorus content, ecological chemometrics and its changing rules. As a result, the content of $\mathrm{C}, \mathrm{N}$ and $\mathrm{P}$ in soil was significantly increased after Conyza canadensis invasion, there was an extremely significant positive correlation among the three elements $(P<0.01)$. Different soil communities at different depths and their interactions have significant effects on soil total nitrogen $(P<0.01)$. $\mathrm{N}$ is the factor of limitting the growth of Conyza Canadensis. There is also a significant positive correlation between the three C:N, C:P and N:P in the soil. N:P changes steadily, and $\mathrm{C}: \mathrm{N}, \mathrm{C}: \mathrm{P}$ have high levels of variation, it may be related to the great change of soil total carbon content.
\end{abstract}

Keywords: environmental pollution $\left(\mathrm{CO}_{2}\right)$, services trade, EKC hypothesis, dynamic GMM panel

\section{Introduction}

Ecological chemometrics is a new science which studies the energy of ecosystem and balance of chemical elements in ecosystem [1]. In recent years,

*e-mail: cuidongw@126.com researches at home and abroad can be divided into global regional scale, functional group or ecosystem scale and individual level [2]. Internal research on the characteristics of ecological started late, but developed rapidly. Most studies on the ecological stoichiometric characteristics of plants focus on the changes of the ecological stoichiometric characteristics of plant organs, however, more and more attention has been paid to the ecochemometrics of soil after invasion [3-5]. 
Soil is an important part of the ecosystem. Carbon, nitrogen and phosphorus in soil are of great significance to plant growth and development. By different plants have different absorption of soil $\mathrm{C}, \mathrm{N}$ and $\mathrm{P}$ nutrient elements, soil ecological stoichiometric characteristics can be used to indicate the status of alien invasive plants [6]. Soil total carbon, total nitrogen, total phosphorus in soil and its stoichiometric ratio are important indexes to measure the balance of multiple elements energy of ecosystem and the composition of soil organic matter and quality. [7]. Studies have shown that C:P and N:P in ecological stoichiometric characteristics of internal different terrestrial ecosystems are higher than global average, indicating that internal terrestrial plants are generally short of phosphorus compared with alien plants [8-9]. In terms of individual study level, the study of JIN Baoshi et al. found that the duration of the invasion years of Spartion Alterniflora Loisel, soil depth, and the interaction between the two had significant effects on soil TC and TN content [10]. XU Sha et al. showed that different dominant glassland plants in different utilization modes and different species of grassland and the interaction between the two had significant effects on soil N P content and C:N C:P and N:P [11]. Guo Ying et al. showed that soil moisture content, soil nutrient and other factors affect the characteristics of ecological stoichiometry [12].

In recent years, the adverse effects of invasive plants in local areas have aroused people's attention. Studies show that invasive plants affect local plants to grow and develop through allelopathy and litter, and change the original soil nutrient structure [13]. Different invasive plants and the same invasive plants have different effects on soil physical and chemical properties of the soil, which indicates that the invasive effects of invasive plants are diverse. For example, studies have shown that invasive plants can increase, decrease or no significantly change the physical and chemical properties of the soil [14-16]. Taking the study of the effect of soil nutrient content as an example, the invasive plant Ageratina adenophora had significantly increased organic carbon content of the soil and reduced total potassium content, but had no significant effect on soil total nitrogen and phosphorus content [15]. Studies have shown that the invasion of the Ageratina adenophora significantly increased the total nitrogen content in the soil, and reduced the total phosphorus and potassium content [17].

As a typical invasive plant of alien species, the Conyza canadensis is widely distributed in China and has been included in the third batch of alien invasion list in China. Depending on its own advantages, Conyza canadensis can quickly spread and adapt to the local environment, forming dominant communities, impacting on local biodiversity and soil physical and chemical properties [18]. At present, research on Conyza Canadensis smainly focuses on the biological ecology and allelopathy of Conyza canadensis [19-26], there are few studies on the impact of soil environment variety, especially the studies on the change of soil stoichiometric characteristics after the invasion of Conyza canadensis.

It is assumed that after invasion, the content of carbon, nitrogen and phosphorus in soil can be increased to make it grow rapidly and create soil environmental conditions conducive to its own growth, thus accelerating the invasion of Conyza Canadensis.

In this paper, we select the community invaded by Conyza Canadensis in different degrees influence on soil physical and chemical properties in the arid region in YiLi River Valley on Torasu Grassland, study the variation characteristics of the soil carbon, nitrogen, phosphorus and variation law of ecological chemometrics characteristics in different degree of invasion, provide a certain theoretical basis for exploring the invasion mechanism of Conyza Canadensis.

\section{Experimental Design}

Research area overview: YiLi River Valley is located in the west of Xinjiang Tianshan Mountains, surrounded by mountains on three sides. The longitude is $80.09-84.05^{\circ} \mathrm{E}$, and the latitude is $42.15-44.50^{\circ} \mathrm{N}$. The average annual temperature is $10.4^{\circ} \mathrm{C}$, with sufficient sunshine, it is the place with the most abundant precipitation in Xinjiang. The study sample is Torasu Grassland in YiLi River Valley ( $44^{\circ} 01$ ' $35^{\prime \prime}-44^{\circ} 08^{\prime} 96^{\prime}$ 'N, $81^{\circ} 28^{\prime} 40^{\prime \prime}-81^{\circ} 35^{\prime} 14^{\prime \prime} \mathrm{E}$ ), which is about $40 \mathrm{~km}$ away from the city and is a typical mountain grassland. Torasu Grassland belongs to the temperate continental semi-arid area, with an altitude of 900-2100 m. Which has grasslands, mountains, glaciers, rivers and other landforms, grassland resources are the most abundant, tourism and graziery develop well [27]. In recent years, it has been found that the area of grassland decreases, grass quality decreases, and the quantity of poisonous plants increases. Eliminating human interference, alien plant invasion is one of the most important factors [18].

Sample setting and Soil sample collection: In this study, the field sample experimental research method was adopted to observe the invasion status of the Conyza canadensis in the field, which can be roughly divided into the following three invasion communities according to the invasion degree: Mild invasive community (the cover range of Conyza Canadensis is less than 30\%), Moderate invasive community (the cover range of Conyza Canadensis is from $30 \%-80 \%$ ) and severe invasive community (the cover range of Conyza Canadensis is more than 80\%), Indigenous community (mainly grows Artemisia scoparia and Centaurea adpressa). Three parallel sample quadrats $(1 \mathrm{~m} \times 1 \mathrm{~m})$ were randomly setted up in each community, and soil profile was excavated in the quadrats. The soil profile was stratified for sampled at intervals of $10 \mathrm{~cm}$, with a sampling depth of $60 \mathrm{~cm}$. A total of 12 soil profiles and 72 soil samples were collected. The collected soil samples were divided into two parts: one 
was refrigerated for reserve, and the other one was naturally air-dried. After air-drying, the samples were ground and passed through $1 \mathrm{~mm}$ and $0.5 \mathrm{~mm}$ pore size soil sieve respectively. After marking, they were bagged as samples to be tested.

The sample location and soil physical and chemical properties are shown in Table 1 and Table 2.

Determination of soil physical and Chemical properties: The total carbon (TC) content of soil was determined by potassium dichromate - sulfuric acid oxidation method. Soil total nitrogen (TN) was determined by Kjeldahl method. Total phosphorus (TP) content in soil was determined by molybdenumantimony anticolorimetric method, and all the above methods were determined by Bao Shidan soil determing method [28]. Soil moisture content was measured by drying method, soil bulk density is measured by ring knife method, and soil pH by acidity meter [29].

Data processing: Single factor variance analysis is adopted to analysis significant $(\alpha=0.05)$ by software SPSS13.0, with double factor analysis of variance, to analysis the significance $(\alpha=0.05)$ of the invasive degree of the small fleabane and the soil depth, principal component analysis was adopted to analyse the soil physical and chemical factors, to analyse the correlation among carbon, nitrogen, phosphorus content of the soil, chemical metrology characteristic and the physical and chemical factors of the soil. Date statistical analysing and maping by Microsoft Excel 2010.

\section{Results and Discussion}

Content Changes of Carbon, Nitrogen and Phosphorus of the Soil in Different Invasive

Degree Communities by Conyza Canadensis

Soil total carbon content have increased significantly after the invasion of Conyza Canadensis (Fig. 1). With the deepening of the invasion, the content of total carbon in soil keep increasing. The average total carbon content of soil layers in the mild, moderate and severe

Table 1. Sampling information.

\begin{tabular}{lccllll}
\hline The invasion of sample & Longitude & Latitude & & Longitude & Latitude \\
& $(\mathrm{E})$ & (N) & & The invasion of sample & (E) & (N) \\
\hline Indigenous community 1 & $81^{\circ} 30^{\prime} 51^{\prime \prime}$ & $44^{\circ} 3^{\prime} 2.8^{\prime \prime}$ & Moderate invasive community 1 & $81^{\circ} 30^{\prime} 49.9^{\prime \prime}$ & $44^{\circ} 3^{\prime} 3.8^{\prime \prime}$ \\
Indigenous community 2 & $81^{\circ} 30^{\prime} 50.9^{\prime \prime}$ & $44^{\circ} 3^{\prime} 2.9^{\prime \prime}$ & Moderate invasive community 2 & $81^{\circ} 30^{\prime} 49.10^{\prime \prime}$ & $44^{\circ} 3^{\prime} 3.6^{\prime \prime}$ \\
Indigenous community 3 & $81^{\circ} 30^{\prime} 50.5^{\prime \prime}$ & $44^{\circ} 3^{\prime} 2.8^{\prime \prime}$ & Moderate invasive community 3 & $81^{\circ} 30^{\prime} 49.11^{\prime \prime}$ & $44^{\circ} 3^{\prime} 3.7^{\prime \prime}$ \\
Mild invasion community 1 & $81^{\circ} 30^{\prime} 49.7^{\prime \prime}$ & $44^{\circ} 3^{\prime} 3.5^{\prime \prime}$ & Severe invasive community 1 & $81^{\circ} 30^{\prime} 41.6^{\prime \prime}$ & $44^{\circ} 3^{\prime} 4.2^{\prime \prime}$ \\
Mild invasion community 2 & $81^{\circ} 30^{\prime} 50.2^{\prime \prime}$ & $44^{\circ} 3^{\prime} 3.3^{\prime \prime}$ & Severe invasive community 2 & $81^{\circ} 30^{\prime} 41.6^{\prime \prime}$ & $44^{\circ} 3^{\prime} 4.2^{\prime \prime}$ \\
Mild invasion community 3 & $81^{\circ} 30^{\prime} 50.4^{\prime \prime}$ & $44^{\circ} 3^{\prime} 3.5^{\prime \prime}$ & Severe invasive community 3 & $81^{\circ} 30^{\prime} 41.6^{\prime \prime}$ & $44^{\circ} 3^{\prime} 4.2^{\prime \prime}$ \\
\hline
\end{tabular}

Table 2. Soil physicochemical properties at the $0 \sim \sim 60 \mathrm{~cm}$ layer at plots.

\begin{tabular}{lcccc}
\hline The invasion of sample & Water content & Bulk density & Fresh weight & pH \\
\hline Indigenous community & $5.16 \pm 0.02 \mathrm{a}$ & $1.24 \pm 0.07 \mathrm{a}$ & $5.23 \pm 0.19 \mathrm{a}$ & $8.12 \pm 0.08 \mathrm{a}$ \\
& & & & $7.97 \pm 0.16 \mathrm{~b}$ \\
Mild invasion community & $5.01 \pm 0.25 \mathrm{~b}$ & $1.25 \pm 0.06 \mathrm{a}$ & $5.09 \pm 0.19 \mathrm{a}$ & $7.83 \pm 0.21 \mathrm{ab}$ \\
Moderate invasive community & $5.03 \pm 0.27 \mathrm{~b}$ & $1.27 \pm 0.04 \mathrm{a}$ & $4.99 \pm 0.19 \mathrm{ab}$ & \\
& & & & $7.86 \pm 0.16 \mathrm{ab}$ \\
\hline
\end{tabular}



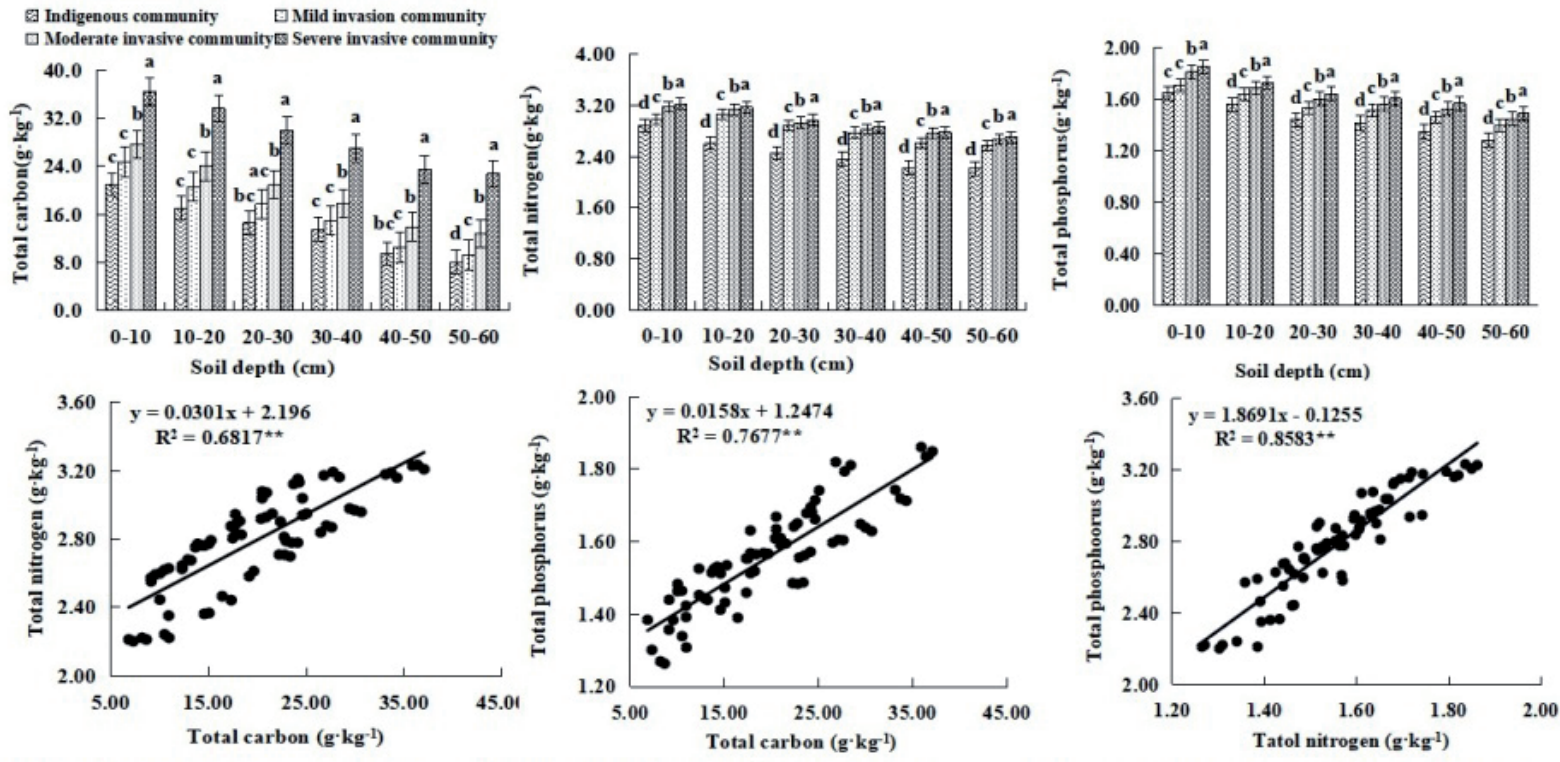

Note:Different lowercase letters indicate significant differences between different plant communities in the same soil layer $(P<0.05)$, the figure below is the same.

Fig. 1. Carbon, nitrogen and phosphorus content distribution in the grassland soil under the invasion of Conyza Canadensis L. Regression analysis of soil TC, TN and TP content in the Conyza Canadensis L.

invasive communities increased by $16 \%, 23 \%$ and $52 \%$ respectively compared with that of the indigenous communities. With the deepening of soil depth, the increase of total carbon content of increased gradually in moderate and severe invasive communities, with the maximum increase of $38 \%$ and $78 \%$ at a depth of $50-60 \mathrm{~cm}$. There is a little different in apperance of the mild invasive communities, with a large increase in the three soil layers at a depth of $0-30 \mathrm{~cm}$, and the largest increase appeared in the soil layer of $20-30 \mathrm{~cm}$, it is $22 \%$.

The total nitrogen content of soil increased significantly after invasion of Conyza Canadensis (Nitrogen content in) each soil layer increased by an average of $15 \%, 19 \%$ and $21 \%$ in mild, moderate and severe invasive communities compare with that of the indegenous communities. So the increasing trend of soil total nitrogen content increased with the severer of the invasion degree. In the soil layer at a depth of $20-30 \mathrm{~cm}$ and $30-40 \mathrm{~cm}$, the invasive communities of the three increased at the same rate, $18 \%, 20 \%$ and $21 \%$ respectively. At a depth of $0-10 \mathrm{~cm}$ in the soil layer, the growth rate of the mild, moderate and the severe invasive communities were $3 \%, 10 \%$ and $12 \%$ respectively, growth rate in mild invasive communities was the smallest. The maximum growth rate of soil total nitrogen content in the three invasive communities appeared in the soil layer of 40-50 cm depth.

The change of total phosphorus content in soil was consistent with that of total nitrogen in soil after Conyza Canadensis invaded. The mild, moderate and severe invasive communities increased by an average of $7 \%$, $11 \%$ and $14 \%$ compared with indigenous communities.
The total phosphorus content of mild invasive communities increased with the deepening of soil layer. There was the difference between moderate and severe invasive communities. The increase rate in $0-10 \mathrm{~cm}$ depth in soil layer was higher than that at $10-20 \mathrm{~cm}$ depth in soil layer, and the increase rate at $20-30 \mathrm{~cm}$ depth in soil layer was higher than that at $30-40 \mathrm{~cm}$ depth in soil layer.

As shown in Table 3, both soil depth and invasion degree have significant influence on total nitrogen and total phosphorus, and invasion degree has a significant influence on soil total carbon. The interaction between the two only had a significant effect on soil total nitrogen, and no significant effect on total carbon and total phosphorus in soil. Total carbon, total nitrogen and total phosphorus have extremely significant correlation. The correlation analysis of the three elements of $\mathrm{C}, \mathrm{N}$ and $\mathrm{P}$ showed that the correlation ratio between total nitrogen and total phosphorus is the highest, as high as 0.926 , and the linear fitting relationship between the two is also the most significant, and the slope shows that the changes between the two tend to be synchronize. The correlation ratio of total carbon, total nitrogen and total phosphorus were slightly lower $(0.826$ and 0.872 , respectively), the linear fitting relations were good, with significant positive correlation.

Soil C, N and P play an important role in the growth and development of plants, and the changes can reflect the growth status of invasive plants. When alien plants invade, they usually change local soil environment and create an appropriate growth environment by withered fallen and scattered matters or allelopathic substances, and.create an appropriate growing environment, they 
usually inhibit the other plants to grow and develop. The content (of T, N, P) is mainly related to the restitution of animals' and plants' residues, microbial decomposition and root absorption [31]. According to the research of GAO Xingxiang, Chen Liping et al., Conyza Canadens have an effect of allelopathy on other plants after invasion [32-33].

According to correlation coefficient analysis, soil $\mathrm{C}, \mathrm{N}$ and $\mathrm{P}$ all have a significant relationship with each other, and there is a high synchronous relationship between total nitrogen and total phosphorus. In this study, the total carbon content of soil increased significantly with the deepening of the invasion degree of Conyza Canadens, the total carbon content of soil in severe invasive communities was the highest. From the perspective of soil layer, there is a great impact on the total carbon content of the three soil layers at $0-30 \mathrm{~cm}$ depth in the mild invasive communities. This is consistent with studies on other invasive plants: the soil total carbon content in Yanghe estuarine wetland was increased under the invasion of Spartina Alterniflora in interflower [34] by Yang Lin (2007). Hou Tao et al. [35] showed that the soil organic matter content was increased after the invasion of Conyza Canadens.

Soil total nitrogen and total potassium content were increased after invasion of Conyza Canadens, but both of the two increased smaller than that of the total carbon. It may be that the absorption of $\mathrm{C}, \mathrm{N}$ and $\mathrm{P}$ elements in soil by Conyza Canadens was less than that of the supplement of $\mathrm{C}, \mathrm{N}$ and $\mathrm{P}$ by plant residues.The results showed that Conyza Canadens has different effects on the cycling of $\mathrm{C}, \mathrm{N}$ and $\mathrm{P}$ elements in soil, and has little effect on the promotion of $\mathrm{N}$ and $\mathrm{P}$ elements, or the growth and development of Conyza Canadens has a high demand for $\mathrm{N}$ and $\mathrm{P}$ elements, which need a further study. This is different from the effect of invasive plant Spartina alterniflora on soil total potassium and total phosphorus $[15,17]$.

Soil total nitrogen and total phosphorus contents were significantly affected by the invasion degree and soil depth of and the increase of both were lower than those of soil total carbon. The analysis from the point of view of soil depth, oil bulk density decreased and promoting the migration of $\mathrm{C}, \mathrm{N}$ and $\mathrm{P}$ elements between soil layers after invasion of Conyza Canadens, which was beneficial to increase the content of $\mathrm{C}, \mathrm{N}$ and $\mathrm{P}$ in soil. This is consistent with research of ZHOU Lilei's [36] on Yili Grassland soil. The interaction between different invasion degree and soil depth only affected soil total nitrogen, which indicated that the change of $\mathrm{N}$ element in soil was affected by the two. It was not comprehensive to analyze the effect of different invasion degree and soil depth on soil total nitrogen by single analysis of different degrees of invasion.

\section{Ecological Stoichiometric Characteristics in Different Degrees of Invasion by Conyza Canadens}

Soil C:N showed an increasing trend at 0-60 cm depth in soil layer after the invasion of Conyza Canadensis (the severe invasive community increased significantly) (Fig. 2), and it changed significantly with the invasion degree and soil depth (Table 3). The $\mathrm{C}: \mathrm{N}$ variation ranges in indigenous community, mild invasive community, moderate invasive community and severe invasive community are 3.63-7.24, 3.59-8.31, 4.79-8.69 and 8.41-11.29, respectively, the average values are 5.55, 5.69, 6.60 and 9.71 respectively, and variation coefficients are $25 \%, 31 \%, 23 \%$ and $12 \%$, respectively.

The changes of soil C:P and C:N are basically the same, and both continue increasing at $0-60 \mathrm{~cm}$ depth in soil layer, and change significantly with the invasion degree and soil depth. The C:P values in indigenous community, mild invasive community, moderate invasive community and severe invasive community were 6.29-12.74, 6.64-14.50, 8.83-15.27 and 15.02-19.69, respectively, the average values were $9.45,10.40,12.00$ and 17.45 respectively, and variation coefficients were $26 \%, 30 \%, 22 \%$ and $12 \%$, respectively.

Soil N:P continued to increase at $10-60 \mathrm{~cm}$ depth in soil layer (at $0-10 \mathrm{~cm}$ depth in soil layer, in moderate and severe invasion communities $\mathrm{N}: \mathrm{P}$ showed a decreasing trend), and other soil layers showed different
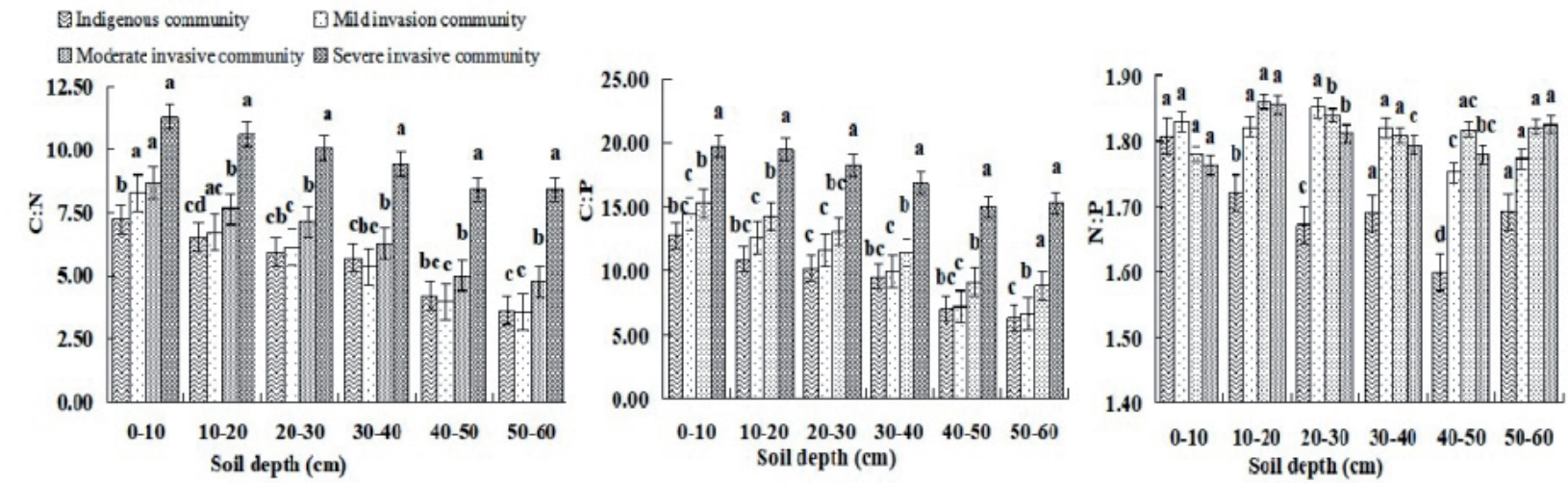

Fig. 2. Chenges of soil C:N, C:P and N:P in the grassland soil under the invasion of Conyza Canadensis L. 
Table 3. Analysis of soil nutrient content and its quantitative ratio at different depts and different communities.

\begin{tabular}{|c|c|c|c|c|c|c|c|}
\hline & df & TC & $\mathrm{TN}$ & TP & $\mathrm{C}: \mathrm{N}$ & $C: P$ & $N: P$ \\
\hline Soil depth $(X)$ & 5 & $P<0.05$ & $P<0.01$ & $P<0.01$ & $P<0.01$ & $P<0.01$ & $P<0.01$ \\
\hline Invasive community(Y) & 3 & $P<0.01$ & $P<0.01$ & $\mathrm{P}<0.01$ & $P<0.01$ & $P<0.01$ & $P<0.01$ \\
\hline \multirow{2}{*}{$X \times Y$} & \multirow{2}{*}{15} & $F=0.556$ & $F=18.603$ & $F=0.938$ & $F=0.707$ & $\mathrm{~F}=0.830$ & $\mathrm{~F}=2.931$ \\
\hline & & $P>0.05$ & $P<0.05$ & $P>0.05$ & $P>0.05$ & $P>0.05$ & $P<0.05$ \\
\hline
\end{tabular}

increases with the deepening of invasion degree. Invasion degree, soil depth and their interaction all have significant effects on N:P (Table 3). N:P in indigenous, mild, moderate and severe invasive communities was $1.60-1.81,1.75-1.85,1.78-1.86$ and 1.76-1.86, respectively, average values were $1.70,1.81,1.82$ and 1.80 respectively, and variation coefficients were $4 \%$, $2 \%, 1 \%$ and $2 \%$, respectively.

The relationships between stoichiometric ratios of different communities with different degrees of invasion is inconsistent. The average values of C:P, C:N and $\mathrm{N}: \mathrm{P}$ in soils in indigenous community were 9.4, 5.5 and 1.7, respectively. The average values of C:P, C:N and $\mathrm{N}: \mathrm{P}$ in soil of mild invasive communities were 5.69, 10.40 and 1.81, respectively. The stoichiometric ratios of indigenous and mildly invasive communities were the same: $\mathrm{C}: \mathrm{P}>\mathrm{C}: \mathrm{N}>\mathrm{N}: \mathrm{P}$, all of which were lower than the national soil average values of $12.3,52.64$ and 4.2 [30]. The soil average values of $\mathrm{C}: \mathrm{P}, \mathrm{C}: \mathrm{N}$ and $\mathrm{N}: \mathrm{P}$ in moderate invasive soil communities were $6.60,12.00$ and 1.82, respectively. The average values of soil C:P, $\mathrm{C}: \mathrm{N}$ and $\mathrm{N}: \mathrm{P}$ in severe invaded communities were 9.71,
17.45 and 1.80, respectively. The stoichiometric ratios of moderate and severe invaded communities were the same: $\mathrm{C}: \mathrm{N}>\mathrm{C}: \mathrm{P}>\mathrm{N}: \mathrm{P}$.

As shown in Table 4, soil total carbon, total nitrogen and total phosphorus are significantly related to soil moisture content and bulk density, while soil total phosphorus is significantly related to fresh weight and $\mathrm{pH}$ value. Soil C:N and C:P have significant correlation with soil bulk density. C:P was related to soil $\mathrm{pH}$ value, N:P was related to moisture content. There was a correlation between carbon in soil, and soil total carbon, total nitrogen, total phosphorus, and C:P are all significantly positive correlated with $\mathrm{C}: \mathrm{N}$, and $\mathrm{N}: \mathrm{P}$ and $\mathrm{C}: \mathrm{P}$ are also significantly positively correlated. It can be seen that the content of $\mathrm{C}, \mathrm{N}$ and $\mathrm{P}$ in soil is mainly affected by water content and bulk density, and the factors affecting its stoichiometric indexes are soil bulk density and $\mathrm{pH}$ value.

According to the principal component analysis in Table 5, the cumulative contribution rate of the first three principal components is $93.4 \%$. The first principal component has a high correlation with

Table 4. Correlation coefficients of TC, TN, TP contents and stoichiometric ratios with soil physicochemical properties.

\begin{tabular}{|c|c|c|c|c|c|c|}
\hline & TC & TN & TP & $\mathrm{C}: \mathrm{N}$ & C:P & $N: P$ \\
\hline Water content & $-0.021^{*}$ & $-0.075^{\star}$ & $0.021^{*}$ & 0.041 & -0.025 & $-0.129^{*}$ \\
\hline Bulk density & $0.457^{\star \star}$ & $0.523^{\star \star}$ & $0.624^{\star \star}$ & $0.471^{\star \star}$ & $0.388^{* \star}$ & -0.205 \\
\hline Fresh weight & 0.012 & 0.102 & $0.258^{\star}$ & 0.225 & -0.056 & -0.098 \\
\hline $\mathrm{pH}$ & 0.022 & -0.071 & $0.029^{\star}$ & 0.143 & $0.019^{*}$ & 0.063 \\
\hline $\mathrm{C}: \mathrm{N}$ & $0.599^{\star *}$ & $0.644^{* *}$ & $0.655^{\star *}$ & & $0.482^{* *}$ & 0.071 \\
\hline C:P & 0.938 & 0.774 & 0.814 & $0.482^{* \star}$ & & $0.042^{*}$ \\
\hline $\mathrm{N}: \mathrm{P}$ & 0.118 & -0.002 & -0.114 & 0.071 & 0.475 & \\
\hline
\end{tabular}


Table 5. Principal component load matrix.

\begin{tabular}{cccccc}
\hline Component & Contrbution(\%) & Water content & Bulk density & Fresh weight & pH \\
\hline 1 & 53.6 & 0.628 & 0.545 & 0.897 & 0.805 \\
2 & 23.9 & -0.510 & 0.776 & 0.132 & -0.275 \\
3 & 15.9 & & & -0.175 & -0.440 \\
\hline
\end{tabular}

soil $\mathrm{pH}$, fresh weight and water content. The second principal component has a higher correlation with soil bulk density and water content. The third principal component had a high correlation with soil moisture content and $\mathrm{pH}$ value.

The results showed that the physical and chemical properties of the soil after the invasion of Conyza Canadensis drove the changes of $\mathrm{C}, \mathrm{N}$ and $\mathrm{P}$ content and their ecological stoichiometric characteristics in grassland soil, and the bulk density and $\mathrm{pH}$ value of the soil had a great impact on the changes of $\mathrm{C}$, $\mathrm{N}$ and $\mathrm{P}$ content and their ecological stoichiometric characteristics in grassland soil.

Ecological stoichiometric studies show that soil C, $\mathrm{N}$ and $\mathrm{P}$ and their stoichiometric ratios are significantly correlated, and there is a coupling relationship between them [6]. This study found that there was a most significantly positive correlation between soil total carbon, total nitrogen and total phosphorus; $\mathrm{C}$ : $\mathrm{N}$ had a most significantly positive correlation with soil total carbon, total nitrogen and total phosphorus; and $\mathrm{C}$ : $\mathrm{N}$, $\mathrm{C}$ : $\mathrm{P}$ and $\mathrm{N}$ : $\mathrm{P}$ had a significant positive correlation.

Analysis from the variation degree of stoichiometric ratios of $\mathrm{C}, \mathrm{N}$ and $\mathrm{P}$ in soil, there has been a decline in all of them with the deepening of the invasion by Conyza Canadens. The variation degree of N: P in soil was lower and variation degree of $\mathrm{C}$ : $\mathrm{N}$ and $\mathrm{C}$ : $\mathrm{P}$ were higher, which might be related to the change of soil total carbon. The decrease of variation degree indicated that the accumulation and consumption of soil nutrients tended to be stable with the establishment of dominant community of Conyza Canadens.

Invasion of Conyza Canadens increased C:N, $\mathrm{C}: \mathrm{P}$ and $\mathrm{N}: \mathrm{P}$ to a certain extent. It can be seen from different invasive communities that the stoichiometric ratios of soil were changed. However, soil C:N, C:P and $\mathrm{N}: \mathrm{P}$ were still lower than the national average soil values: 12.3, 52.64 and 4.2 [30]. With the deepening of the invasion and depth of soil, soil $\mathrm{C}: \mathrm{P}$ and $\mathrm{C}: \mathrm{N}$ have a great significant relationship with soil total nitrogen and total phosphorus, which may be related to the increasing content of soil total carbon. This is consistent with the results of Xing Dan et al [37].
The decomposition and formation of organic matter can change the relationship among soil nutrient elements such as $\mathrm{C}, \mathrm{N}$ and $\mathrm{P}$ in a certain proportion. The stoichiometric ratios of $\mathrm{C}, \mathrm{N}$ and $\mathrm{P}$ in different soils have different indicative meanings [11]. Soil C:N is the sensitive indicator of soil quality, which can be used to measure the balance between soil carbon and nitrogen elements, which can reflect the decomposition rate of organic matter and the cycling status of both elements [38]. In this paper, the soil C: $\mathrm{N}$ of indigenous communities is low, and it increases significantly with the invasion of Conyza Canadens. It shows that the invasion of Conyza Canadens increases the decomposition speed of soil microbial organic matter and promotes the cycling of carbon and nitrogen elements. When soil C:P was lower than 200, it was considered that soil microbial biomass carbon had a short increase and phosphorus had net mineralization [39].

With the invasion of Conyza Canadens, soil bulk density and soil $\mathrm{pH}$ value were reduced, soil compactness and salinity were reduced, which was beneficial to the migration of phosphorus among soil layers, the effective components of phosphorus in soil were increased, and the total phosphorus content in soil was increased. The change rate of the total carbon content in soil was great, so C:P was still increasing with the invasion of Conyza Canadens finally. $\mathrm{N}$ and $\mathrm{P}$ elements in soil are functional elements of plants, and it is believed that the elements which restrict plant growth are $\mathrm{N}$ and $\mathrm{P}$ elements with less supply, rather than $\mathrm{C}$ elements [6]. Soil $\mathrm{N}: \mathrm{P}$ is used to indicate the soil nutrients supply to plants and for soil nutrient restriction index [40]. Koerselman et al. [41] hold that $\mathrm{N}: \mathrm{P}<14$ indicates that the ecosystem is limited by $\mathrm{N}$ elements. In this study, N:P increased with the invasion of Conyza Canadens, but all the values were lower than the value, so the growth of Conyza Canadens is limited by $\mathrm{N}$ element.

In conclusion, the changes of soil $\mathrm{C}: \mathrm{N}, \mathrm{C}: \mathrm{P}$ and $\mathrm{N}$ : $\mathrm{P}$ after Conyza Canadens invaded are closely related to soil $\mathrm{C}, \mathrm{N}$ and $\mathrm{P}$, which can be better used to indicate the limited elements of soil nutrients and their availability. 
According to the correlation analysis, soil bulk density and water content have a great influence on soil chemometric characteristics. Principal component analysis further proves that soil bulk density, $\mathrm{pH}$ value and water content are the main influencing factors. The results showed that the soil moisture content and fresh weight decreased significantly after the invasion of Conyza Canadens, soil alkalinity reduced. According to the analysis, the moderate invasive community had a great influence on soil $\mathrm{pH}$ value. This may be related to the release of acidic substances during the decomposition of plant residues and root exudation. Liu Wenlong et al. [42] showed that soil $\mathrm{pH}$ value could change the decomposition rate of organic matter by affecting soil microbial activity, and affect the cycling of $\mathrm{N}$ and $\mathrm{P}$ elements, thereby affecting the chemometric characteristics of soil [43-44], which is consistent with the results of this study.

\section{Conclusion}

In this paper, soil $\mathrm{C}, \mathrm{N}, \mathrm{P}$ and their stoichiometric characteristics were studied in three different degrees of invasive communities and indigenous communities of Conyza Canadens. This study holds that:

1. Soil $\mathrm{C}, \mathrm{N}$ and $\mathrm{P}$ contents were significantly increased in different invasive communities of Conyza Canadens. Different depth soil layers, different communities and their interaction had significant effects on soil total nitrogen $(P<0.01)$.

2. The eco-chemometric characteristics have shown that $\mathrm{C}: \mathrm{N}$ and $\mathrm{C}: \mathrm{P}$ changed obviously, and both of the two have a high degree of variation, which might be related to the change of soil total carbon content. Through the analysis of the eco-stoichiometric ratio, it was concluded that the limiting element of soil nutrients for the growth of Conyza Canadens in this study area was $\mathrm{N}$.

3. There was a significant positive correlation among soil $\mathrm{C}, \mathrm{N}$ and $\mathrm{P}(P<0.01)$, with a good linear fitting relationship. There was also a significant positive correlation among soil C: N, C: P and N: P $(P<0.05)$.

\section{Acknowledgement}

The authors would like to thank the "by the Tianshan Youth Program, a special talent program in Xinjiang Uygur Autonomous region" (Fund number: 2018Q076) for its financial support.

\section{Conflict of Interest}

The authors declare no conflict of interest.

\section{References}

1. WANG S.Q., YU G.R. Ecological stoichiometry characteristics of ecosystem carbon, nitrogen and phosphorus elements. Journal of Acta Ecologica Sinica, 28 (8), 3937, 2008.

2. NIKLAS K.J., COBB E.D. N, P, and C Stoichiometry of Eranthis hyemalis (Ranunculaceae) and the allometry of plant growth. American Journal of Botany, 92 (8), 1256, 2005.

3. RAN Y.N. Effects of relative supplies of nitrogen and phosphorus on growth and stoichiometric characteristics of Suadea salsa. University of Chinese Academy of Sciences, China, 2017.

4. MA M.R., YANG J., WANG Q., TANG L.H., YOU W.H. Nitrogen and phosphorus stoichiometry and invasion mechanisms of Solidago canadensis L. in riparian zone. China Environmental Science, 34 (6), 1531, 2014.

5. ZENG D.P., JIANG L.L., ZENG C.S., WANG W.Q., WANG C. Reviews on the ecological stoichiometry characteristics and its applications. Journal of Acta Ecologica Sinica, 33 (18), 5484, 2013.

6. YANG H.M., WANG D.M. Advances in the study on ecological stoichiometry in grass-environment system and its response to environmental factors. Journal of Acta Prataculturae Sinica, 20 (2), 244, 2011.

7. ZENG Q.C., LI X., DONG Y.H., AN S.S. Ecological stoichiometry of soils in the Yanhe watershed in the Loess Plateau: The influence of different vegetation zones. Journal of Natural Resources, 31 (11), 91, 2016.

8. TU C.Y. Study on stoichiometric characteristics of invasive plant Flaveria Bidentis. Chinese Academy of Agricultural Sciences, 2013.

9. JIN B.S., YAN H.Y., WANG W.Q., ZENG C.S. Changes of soil carbon, nitrogen and phosphorus and stoichiometry characteristics in marsh invaded by Spartina alterniflora. Chinese Journal of Applied Ecology, 28 (5), 1541, 2017.

10. REN S.J., YU G.R., TAO B., WANG S.Q. Leaf nitrogen and phosphorus stoichiometry across 654 terrestrial plant species in NSTEC. Chinese Journal of Environmental Science, 28 (12), 2665, 2007.

11. XU S., GONG J. R., ZHANG Z.Y., LIU M., WANG Y.H., LUO Q. P.The ecological stoichiometry of dominant species in different land uses type of grassland. Journal of Acta Prataculturae Sinica, 23 (6), 45, 2014.

12. GUO Y., LI J., ZHANG Y.Y., NIU Y.Q., ZHOU W.W., WANG Y.H. Research Advances in soil and plant stoichiometry in terrestrial ecosystems in China. Journal of Anhui Agricultural Science, 44 (16), 1, 2016.

13. BU N.S., HU Y., YANG X., ZHANG X., WANG J., LI B., FANG C.M., SONG Y. Effects of Spartina alterniflora invasion on soil physical and chemical properties in wetlands of the Yangtze river estuary. Resources and Environment in the Yangtze Basin, 26 (01), 100, 2017.

14. SHEN L.H. Study on allelo pathy mechanism in the invasion of alien plant Solidago canadensis L. Fujian Agriculture and Forestry University, China, 2007.

15. NIU H.B., LIU W.X., WAN F.H. Invasive effects of Ageratina adenophora sprengel (Asteraceae) on soil microbial community and physical and chemical properties. Journal of Acta Ecologica Sinica, 27 (7), 3051, 2006. 
16. LIANG L., YE X.Q., WU M., SHAO X.X., LI C.M. Invasion effects of Solidago canadensison soil nutrients and active organic carbon components in reclamation district of Hangzhou Bay wetland. Soils, 48 (4), 680, 2016.

17. DENG D.D., LIU Q., JIANG Z.L., LIU W.X., WAN F.H., LI Z.Y. Differences in soil enzymatic activities and soil nutrients of Ageratina adenophora and different plant communities.Ecology and Environment Sciences, 9, 14661471, 2015.

18. LU P., LIANG Q.L., WANG W.H., CHEN S.F. Distribution,harms and control measures of the main poisonous plants in the natural grassland of Yili Valley. Journal of Weed Science, 2, 41, 2009.

19. YANG Y., CHEN Y.N., LI W.H., CHEN Y.P. Soil Organic Carbon Distribution of Different Vegetation Types in the Ili River Valley. Journal of Acta Geographica Sinica, 605612, 65 (5), 2010.

20. SHIELDSA E.J., DAUER J.T., VAN GESSEL M.J., SHIELDS E.J., NEUMANN G. Horseweed (Conyza canadensis) seed collected in the planetary boundary layer. Journal of Weed Science, 54 (6), 1063, 2006.

21. BRUCE J.A., KELLS J.J. Horseweed (Conyza canadensis) control in no-till soybean (Glycine max) with preplant and preemergence herbicides. Weed Technology, 4 (3), 642, 1990.

22. ZHANG H.Y., LUO X., ZHANG M. The progress of Studies on the allelopathy mechanism of alien invasive plant Conyza canadensis (L.) Cronq. Journal of Hunan Ecological Science, 2 (4), 29, 2015.

23. ZHANG S. Study on invasive biology of alien plant Conyza canadensis. Shanghai Normal University, China, 2010.

24. XIAO C.P., YANG L., YANG L.M. Allelopathy effect of Conyza canadensis decomposition on two tested plants. Journal of Acta Agriculturae Boreali-occidentalis Sinica, 20 (12), 130, 2011.

25. GAO X.X., LI M., FANG F., LI J. Effects of aqueous extractions of Conyza canadensis on germination and seedling growth of four weeds. Pratacultural Science, 32 (1), 48, 2015.

26. GAO X.X., LI M., YU J.L., SONG G.C., LI R.J. Bioassay on the herbicidal activity of extracts from Erigeron canadensis. Journal of Plant Resources and Environmen, 15 (1), 18, 2006.

27. GAO Y., ZHU C.H., LI X.F., LEI Z.M., YU S.H. Allelopathy of Conyza canadensis on seed germination and seedling growth of three types of weed. Hubei Agricultural Sciences, China, 51 (15), 003230, 2012.

28. BAO S.D. Agricultural chemistry analysis of soils. Beijing: China Agriculture Press, 2000.

29. Institute of Soil Science, Chinese Academy of Sciences-Soil Features Analysis. Shanghai Scientific \& Technical Publishers, China, 1987.

30. TIAN H.Q., CHEN G.S., ZHANG C., JERRY M. MELILLO CHARLES A.S. Hall. Pattern and variation of C:N:P ratios in China's soils: a synthesis of observational data. Biogeochemistry, 98 (1-3), 139, 2010.
31. XU R.H., YE W.H. Biological invasion - theory and practice. Science Press, China, 2003.

32. GAO X.X., LI M., GAO Z.J., SUN T.L., SUN Z.W. Research on allelopathic effects of Conyza canadensis-an invasive species. Journal of Acta Prataculturae Sinica, 18 (5), 46, 2009.

33. CHEN L.P., CAO M.L., MA D.W. Primary study on genetic toxicity of an invasive plant Erigeron canadensis L. Journal of Sichuan Normal University (Natural Science), China, 31 (3), 372, 2008.

34. YANG L. Response of soil carbon, nitrogen and phosphorus ecological stoichiometric characteristics in in the Yanghe estuarine wetland to Spartina alterniflora invasion. Qingdao University, China, 2007.

35. HOU T., PANG C.H., LIU L.W. Correlations between community characteristics of Conyza canadensis and soil factors. Journal of Shanxi Normal University (Natural Science Edition), China, 1, 89, 2017.

36. ZHOU L.L., ZHU H.Z., ZHONG H.P., YANG H., SUO F.Y., SHAO X.M., ZHOU X.J. Spatial analysis of soil bulk density in Yili, Xinjiang Uygur autonomous region, China. Journal of Acta Prataculturae Sinica, 25 (1), 64, 2016.

37. XING D., XIAO J.J., WANG X.H., ZHANG F., HAN S.Y., LUO C.B. Nutrients and ecological stoichiometry characteristics of soil from returning farmland to mulberry field in stony desertification area. Southwest China Journal of Agricultural Sciences, 31 (07), 114, 2018.

38. LI D.W., WANG Z.Q., TIAN H.X., HE W.X., GENG Z.C. Carbon, nitrogen and phosphorus contents in soils on Taibai Mountain and their ecological stoichiometry relative to elevation. Journal of Acta Pedologica Sinica, 54 (1), 160, 2017.

39. JIA Y., XU B.C., LI F.M., WANG X.L. Availability and contributions of soil phosphorus to forage production of seeded alfalfa in semiarid Loess Plateau. Journal of Acta Ecologica Sinica, 27 (1), 42, 2007.

40. AO Y.M.. Study on soil ecological stoichiometey of enclosing life typical steppe. Inner Mongolia Normal University, China, 2012.

41. KOERSELMAN W., MEULEMAN A.F.M. The vegetation $\mathrm{N}: \mathrm{P}$ ratio: A new tool to detect the nature of nutrient limitation. Journal of Applied Ecology, 33, 1441, 1996.

42. LIU W.L., XIE W.X., ZHAO Q.S., ZHU K.J., YU R.R. Spatial distribution and ecological stoichiometry characteristics of carbon, nitrogen and phosphorus in soil in phragmites australis Tidal Flat of Jiaozhou Bay. Journal of Wetland Science, 12 (3), 362, 2014.

43. WANG W.Q., TONG C., JIA R.X., ZENG C.S. Ecological stoichiometry characteristics of wetland soil carbon, nitrogen and phosphorus in different water-flooded frequency. Journal of Soil and Water Conservation, 24 (3), 238, 2010.

44. WANG W. Q., WANG C., ZENG C. S., TONG C.. Soil carbon,nitrogen and phosphorus ecological stoichiometry of phragmites australis wetlands in different reaches in Minjiang River estuary. Journal of Acta Ecologica Sinica, 32 (13), 4087, 2012. 
